\title{
PENGGUNAAN GAME EDUKASI UNTUK MENINGKATKAN HAPALAN ANGKA DI TK DIPONEGORO SURABAYA
}

\author{
${ }^{1}$ Muchamad Arif, ${ }^{2}$ Ida Ayu Puspita Sari, ${ }^{3}$ Lukman Junaedi, ${ }^{4}$ Rofik Jalal Rosyanafi \\ Universitas Narotama \\ ${ }^{1}$ muchamad.arif@narotama.ac.id \\ 2idaayups07@gmail.com \\ 3 lukman.junaedi@narotama.ac.id \\ ${ }^{4}$ rofik.jalal.rosyanafi@narotama.ac.id
}

\begin{abstract}
ABSTRAK
Penelitian ini bertujuan untuk mengetahui penggunaan game edukasi untuk meningkatkan hapalan angka 1-20 di Tk diponegoro surabaya. Sekolah ini terletak di Jalan Kedung Sroko No.17 Surabaya Sample penelitian ini adalah anak-anak kelompok B TK Diponegoro. Penulis menggunakan metode deskriptif kualitatif. Penulis fokus bagaimana menerapkan penggunaan game edukasi untuk meningkatkan hapalan angka 1-20 di Tk diponegoro surabaya. Penulis melakukan observasi selama $3 x$ pertemuan. Setiap pertemuan mereka memainkan game edukasi yang berbeda namun dengan isi materi yang sama. Subjek penelitian adalah TK Diponegoro yang berjumlah 20 siswa. Hasil penelitian menunjukkan bahwa siswa sangat antusias dalam belajar menghapal angka 1-20 serta meningkatkan kemampuan motorik halus anak.
\end{abstract}

Kata Kunci: game edukasi, hapalan, angka 1-20

\begin{abstract}
This study aimed to determine the use of educational games to improve memorization of 1-20 numbers in TK Diponegoro Surabaya. This school is located at Jalan Kedung Sroko No.17 Surabaya. The sample of this study was the children of B group Diponegoro Kindergarten. The authors used descriptive qualitative methods. The author focused on how to apply the use of educational games to improve memorization numbers 1-20 at Tk Diponegoro Surabaya. The author made observations during the $3 x$ meeting. Each meeting, they play a different educational game but with the same content. The subject of the research was Diponegoro Kindergarten with 20 students. The results showed that students were very enthusiastic in learning to memorize numbers 1-20 as well as improving children's fine motor skills..
\end{abstract}

Keywords: educational games, memorizing, numbers 1-20 


\section{PENDAHULUAN}

Perkembangan IPTEK dan seni semakin berkembang pesat, pendidikan anak usia dini atau PAUD juga terspesialisasi. PAUD merupakan suatu lembaga yang bertugas untuk mengembangkan berbagai potensi yang dimiliki anak sebagai bekal dalam kehidupan seharihari dan mempersiapkan diri anak melanjutkan ke tingkat pendidikan selanjutnya. Pembelajaran PAUD dilaksanakan sesuai dengan karakteristik anak, perkembangan zaman, serta perkembangan IPTEK dan seni yang semakin berkembang pesat pada zaman saat ini. Bagi anak usia dini, pembelajaran ialah belajar sambil bermain yang dilakukan secara berulang dan menimbulkan rasa senang pada anak. Dalam proses pembelajaran tentunya diperlukan suatu media sebagai alat yang memudahkan pembelajaran tersebut. Penggunaan media dalam proses pembelajaran harus dapat membangkitkan minat dan keinginan belajar anak, membangkitkan motivasi dan rangsangan kegiatan belajar, bahkan membawa pengaruhpengaruh psikologis terhadap pebelajar anak. Pemakaian media pembelajaran pada tahap orientasi pengajaran sangat membantu keefektifan proses pembelajaran dan penyampaian pesan dan isi pelajaran pada saat pembelajaran. Sesuai dengan majunya perkembangan IPTEK ini, kita dapat menggunakan komputer sebagai media pembelajaran yang menyenangkan. Pada penelitian ini, peneliti fokus pada bagaimana menerapkan penggunaan game edukasi untuk meningkatkan hapalan angka 1-20 di Tk diponegoro Surabaya.

\section{LANDASAN TEORI}

Media adalah alat atau sarana komunikasi (KBBI, 2016). Sedangkan pembelajaran merupakan suatu kegiatan yang melibatkan anak dan guru dalam mengenal dan mempelajari ilmu pengetahuan. Untuk mendukung keberhasilan dan kelancaran dalam kegiatan pembelajaran, diperlukan media penunjang yang banyak macamnya sesuai dengan berbagai karakteristik yang dimiliki setiap anak (Nurseto, 2011). Media pembelajaran dianggap sebagai alat untuk membantu guru dalam kegiatan mengajar agar lebih efektif dan efisien dan menyenangkan bagi anak. Ada beberapa jenis media pembelajaran yang dapat digunakan, seperti media audio, visual, dan audio visual (Hafid, 2011). Media audio hanyalah mengeluarkan suara untuk proses pemahaman, namun ini kurang cocok untuk anak usia dini. salah satu contoh media yang hanya mengeluarkan suara sebagai pusat informasi ialah radio. Media visual merupakan media yang mengandalkan penglihatan saja. Contoh dari media visual ini berupa suatu alat peraga atau poster gambar-gambar. Sedangkan media audio visual berupa televisi dan komputer. Selain manfaat media pembelajaran agar lebih efektif dan efisien, ada beberapa manfaat lainnya yang lebih, seperti yang di identifikasikan oleh (Miftah, 2013): 
1. Penyampaian materi pelajaran dapat di seragamkan

2. Proses pembelajaran lebih jelas dan menarik

3. Proses pembelajaran lebih interaktif

4. Efisien dalam waktu dan tenaga

5. Meningkatkan kualitas hasil belajar anak didik

6. Media memungkinkan proses pembelajaran dapat dilakukan di mana saja dan kapan saja

7. Media dapat menumbuhkan sikap positif pebelajar terhadap materi dan proses belajar.

8. Mengubah peran anak didik ke arah yang lebih positif dan produktif

9. Media dapat membuat materi pelajaran yang abstrak menjadi lebih konkrit

10. Media juga dapat mengatasi kendala keterbatasan ruang dan waktu

11. Media dapat membantu mengatasi keterbatasan indera manusia

Pada pembelajaran dikelas untuk anak TK (5-6 tahun) menggunakan media perangkat keras yaitu komputer. Komputer merupakan salah satu Teknologi Informasi dan Komunikasi (TIK) yang sudah berkembang semakin jauh dan merevolusi kehidupan sekarang. Sebaiknya guru pengajar mengenalkan komputer pada anak didiknya sejak usia dini agar ditingkat pendidikan selanjutnya anak tinggal memantapkan saja pengetahuan IPTEK tersebut. Komputer ini terdiri dari perangkat keras dan perangkat lunak. Perangkat keras komputer seperti layar monitor, cpu, keyboard dan mouse. Sedangkan perangkat lunaknya seperti software yang berjalan pada komputer. Penggunaan komputer dapat mempermudah proses pembelajaran karena anak didik dapat melihat dan mendengar suatu pelajaran. Selain itu, pembelajaran dengan komputer dapat menarik minat belajar anak melalui permainan menggunakan multimedia yang interaktif, gambar dengan suara sehingga tidak membosankan, serta game yang dapat mengalihkan kejenuhan saat belajar. Manfaat dari media komputer pada anak usia dini, yaitu mengembangkan enam aspek perkembangan anak, seperti aspek kognitif, motorik, bahasa, sosial emosional, nilai agama dan moral, dan seni. Sebelum menggunakan media komputer tersebut, anak diberi materi tentang pelajaran yang akan dipelajari dan penjelasan tentang alat komputer serta bagaimana cara menggunakannya. Perangkat lunak yang digunakan yaitu software aplikasi permainan edukatif 


\section{METODE PENELITIAN}

Penelitian ini dilaksanakan di TK Diponegoro Surabaya. Sekolah ini terletak di Jalan Kedung Sroko No.17 Surabaya. Sample penelitian ini adalah anak-anak kelompok B TK Diponegoro. Penulis menggunakan metode deskriptif kualitatif karena penelitian ini dibuat sealami mungkin dan tidak ada paksaan kemampuan anak harus meningkat secara signifikan (Arif, 2020). Penulis fokus bagaimana menerapkan penggunaan game edukasi untuk meningkatkan hapalan angka 1-20 di Tk diponegoro surabaya. Penulis melakukan observasi selama 3x pertemuan. Setiap pertemuan mereka memainkan game edukasi yang berbeda namun dengan isi materi yang sama. Subjek penelitian adalah TK Diponegoro yang berjumlah 20 siswa.

\section{HASIL DAN DISKUSI}

Penelitian ini dilaksanakan selama 3x. Siswa selalu belajar tentang angka setiap pertemuan. Setiap pertemuan mereka memainkan game edukasi tentang angka. Setiap pertemuan mempunyai permainan angka yang berbeda, sehingga mereka lebih antusias dalam memahami angka-angka terutama angka 1-20. Untuk kegiatannya selama 3x pertemuan itu tidak berbeda jauh jadi secara umum akan kami jelaskan seperti dibawah ini.

Pada kegiatan awal, semua siswa melakukan baris berbaris sebelum masuk ke kelas. Kemudian, mereka masuk ke kelas dan duduk di kursi yang telah disediakan. Selanjutnya, mereka berdo'a sebelum memulai pelajaran. Kemudian, para siswa belajar berhitung mulai dari angka 1 sampai angka 20 dalam bahasa Indonesia, bahasa Jawa, bahasa Inggris, bahasa Madura, dan bahasa Arab.

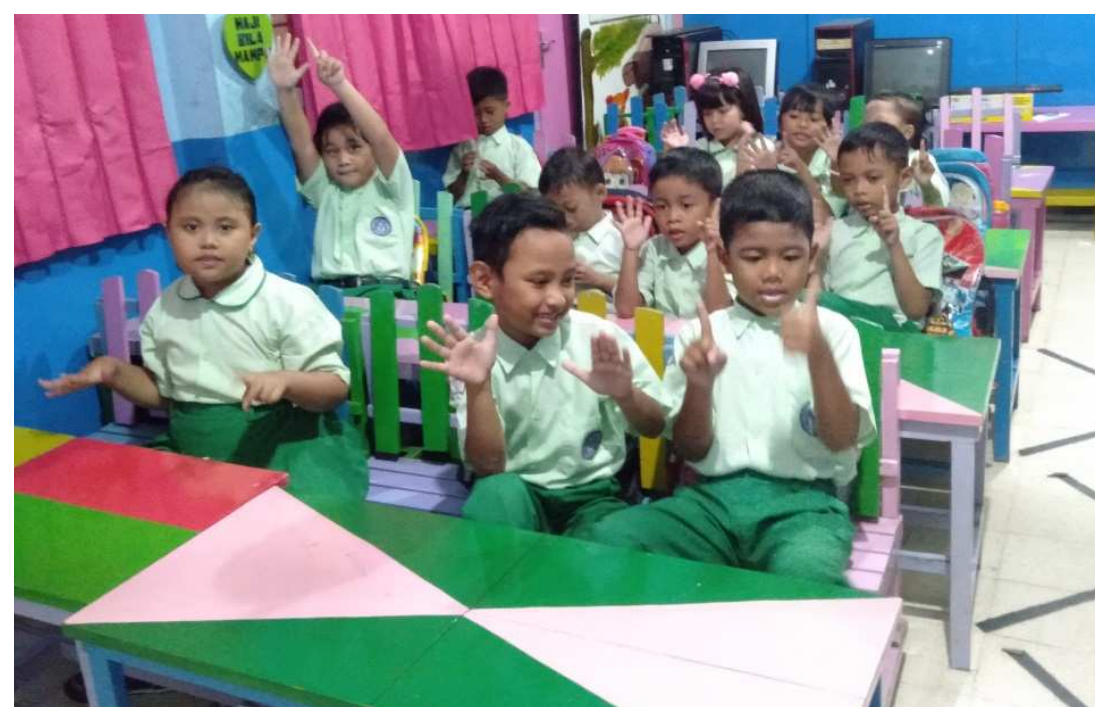

Gambar 1. Siswa belajar berhitung 
Selanjutnya pada kegiatan inti, anak-anak bermain komputer. Caranya : meng-klik titik yang dibawahnya terdapat angka. Angka tersebut harus diurutkan dari yang terkecil ke terbesar dan sebaliknya sampai garis tersambung semua. Kemudian garis itu membentuk sebuah gambar astronot dan pesawat roket.

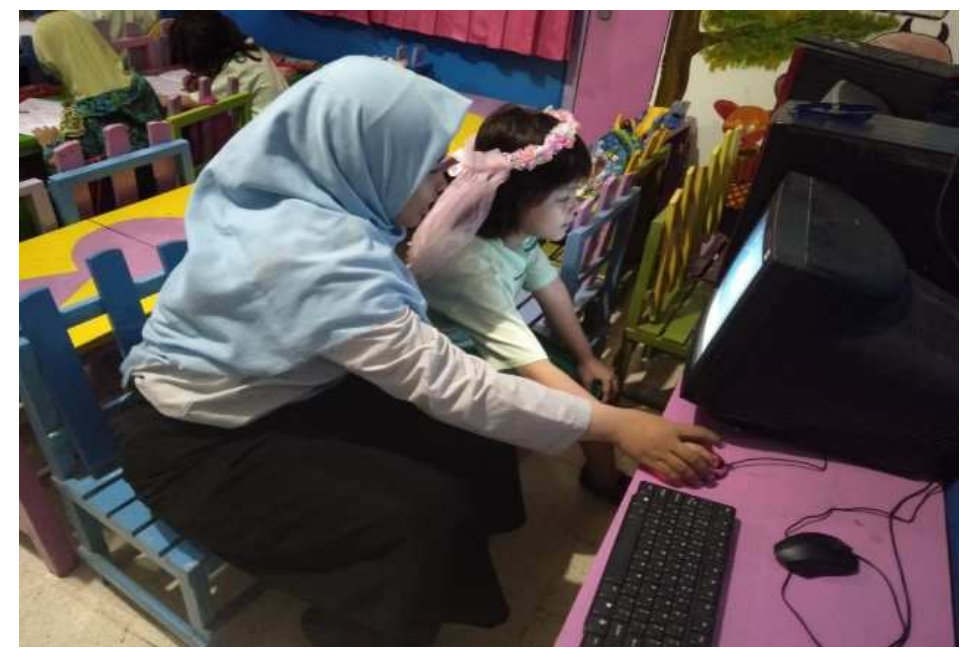

Gambar 2. Guru memberikan contoh bermain game angka

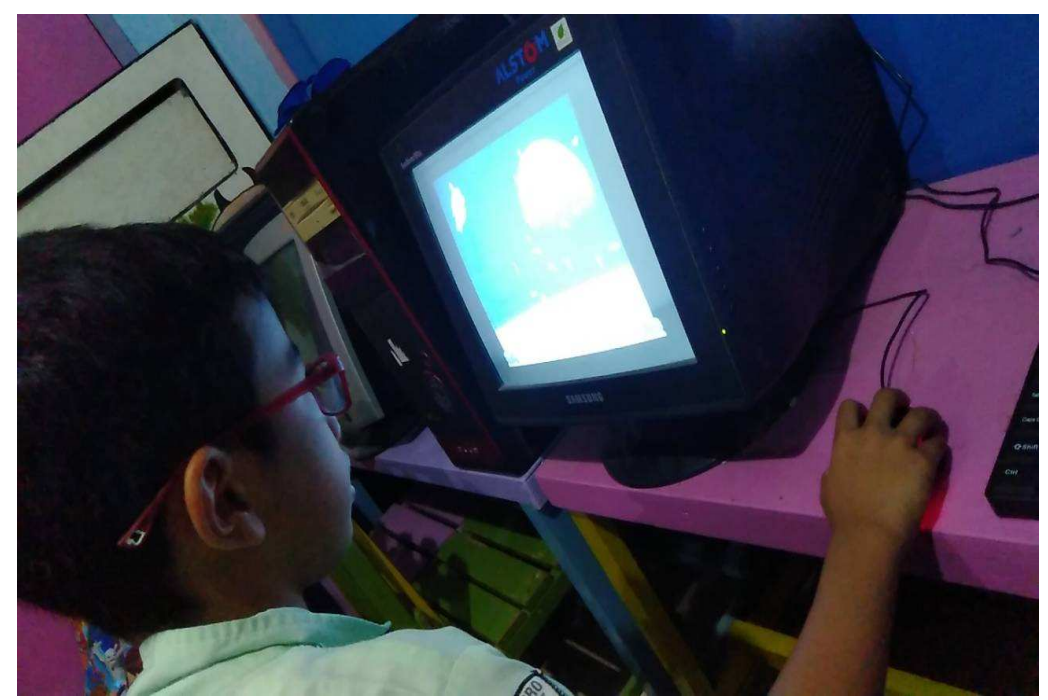

Gambar 3. Siswa bermain game angka

Kemudian, pada akhir pertemuan, guru menanyakan kepada anak didik kegiatan apa saja yang sudah dilakukan hari ini, misalnya "anak-anak hari ini kita belajar apa saja?" selain itu guru juga menanyakan bagaimana perasaan anak-anak saat bermain komputer, apakah 
suka, apakah mau diajak lagi pembelajaran dengan menggunakan komputer. Guru juga bertanya kepada anak didik bagaimana cara bermain komputer yang sudah dilakukan tadi guna mencari tahu seberapa paham anak didik dalam pembelajaran menggunakan komputer hari ini. Kemudian guru menjelaskan lagi cara-cara mengenai pembelajaran bermain angka menggunakan komputer agar anak didiklebih paham. Yang terakhir anak didik diajak berhitung kembali angka 1-20 sambil bernyanyi.

Berdasarkan uraian ditas, kita bisa menyimpulkan bahwa anak-anak menyukai belajar angka dengan bermain game edukasi. Mereka sangat antusias ketika mengklik angka-angka sampai membentuk suatu gambar. Kemudian, anak-anak juga lebih cepat paham karena langsung praktek. Ketika mengklik angka, anak-anak harus bisa mengklik urutan angka sehingga membentuk gambar. Jika mereka salah klik urutan angka maka mereka tidak bisa lanjut ke angka selanjutnya dan gambar tidak bisa terbentuk.

Selain itu, kegiatan ini melatih untuk meningkatkan kemampuan motorik halus anak dengan cara menklik mouse. Bahkan, kegiatan ini bisa menstimulasi kreativitas dan imajinasi anak. Anak-anak berusaha mengingat urutan angka selanjutnya sehingga mereka bisa lanjut klik ke angka selanjutnya atau apabila anak-anak kesulitan untuk mengingat urutan angka, anak-anak berimajinasi urutan garis atau gambar selanjutnya sehingga bisa membentuk suatu gambar yang utuh.

Namun, penerapan game edukasi untuk meningkatkan hapalan angka juga mempunyai kekurangan. Apabila siswa menatap layar monitor terlalu lama, hal ini dapat menyebabkan mata lelah atau mempengaruhi penglihatan anak. (Shofia et al., 2019) mengatakan bahwa penerapan game edukasi dengan menggunakan komputer bisa bermasalah bagi anak yang mempunyai kemampuan motorik halus yang kurang bagus.

\section{KESIMPULAN}

Bermain merupakan suatu kegiatan yang sudah menjadi tuntutan dan kewajiban bagi anak-anak usia dini, sehingga berbagai kegiatan pembelajaran dilakukan dengan macammacam permainan dalam suasana menyenangkan dan dapat merangsang pengetahuan anak serta melibatkan anak secara aktif. Belajar sambil belajar sangatlah disukai anak-anak baik menggunakan media ataupun tanpa media. Dalam dunia pendidikan pemanfaatan media ICT memiliki peran penting guna memenuhi kebutuhan pembelajaran yang mengikuti perkembangan zaman. Pembelajaran dengan media ICT ini juga disukai anak-anak sehingga mempermudah guru dalam memberikan materi pembelajaran sambil bermain. 


\section{DAFTAR PUSTAKA}

Arif, M. (2020). 5 Jurus Jitu Menulis Skripsi Deksriptif Kualitatif. Narotama University Press.

Hafid, H. ab. (2011). Sumber dan Media Pembelajaran. Jurnal Sulesana.

KBBI. (2016). Kamus Besar Bahasa Indonesia ( KBBI ). In Kementerian Pendidikan dan Budaya.

Miftah, M. (2013). FUNGSI, DAN PERAN MEDIA PEMBELAJARAN SEBAGAI UPAYA PENINGKATAN KEMAMPUAN BELAJAR SISWA. Jurnal Kwangsan. https://doi.org/10.31800/jurnalkwangsan.v1i2.7

Nurseto, T. (2011). Membuat Media Pembelajaran yang Menarik - Tejo Nurseto. Jurnal Ekonomi Dan Pendidikan.

Shofia, L., Gempita, V. A., , N., \& Arif, M. (2019). Penerapan Applikasi Edukasi Komputer Untuk Meningkatkan Hapalan Abjad Di Tk Yapita Surabaya. MOTORIC. https://doi.org/10.31090/m.v3i1.888 